\title{
Integration of Local and Regional Species-Area Relationships from Space-Time Species Accumulation
}

\author{
Jason D. Fridley, ${ }^{1, \star}$ Robert K. Peet, ${ }^{1, \dagger}$ Eddy van der Maarel, ${ }^{2, \uparrow}$ and Jo H. Willems ${ }^{3, \$}$
}

1. Department of Biology, University of North Carolina, Chapel Hill, North Carolina 27599;

2. Community and Conservation Ecology Group, University of Groningen, P.O. Box 14, 9750 AA Haren, The Netherlands; 3. Department of Plant Ecology, Utrecht University, Sorbonnelaan 16, 3508 TB Utrecht, The Netherlands

Submitted October 14, 2005; Accepted March 16, 2006; Electronically published June 5, 2006

ABSTRACT: A long-standing observation in community ecology is that the scaling of species richness, as exemplified by species-area curves, differs on local and regional scales. This decoupling of scales may be largely due to sampling processes (the increasing constraint imposed by sampling fewer individuals at fine scales), as distinct from ecological processes, such as environmental heterogeneity, that operate across scales. Removal of the sampling constraint from fine-scale richness estimates should yield species-area curves that behave like those of the regions in which they are embedded, but an effective method for this removal has not been available. We suggest an approach that incorporates the manner in which small areas accumulate species over time as a way to remove the signature of sampling processes from fine-scale species-area curves. We report for three species-rich grasslands from two continents how local plant species richness is distributed through time at multiple, nested spatial scales, and we ask whether samplingcorrected curves reflect the spatial scaling of richness of each larger floristic province. Our analysis suggests that fine-scale values of richness are highly constrained by sampling processes, but once these constraints are removed, the spatial scaling of species richness is consistent from the scale of individuals to that of an entire province.

Keywords: species-area curve, species-time curve, Preston, species richness, scale dependence, grassland.

\footnotetext{
* Present address: Department of Biology, Syracuse University, 130 College Place, Syracuse, New York 13244; e-mail: fridley@unc.edu.

† E-mail: peet@unc.edu.

₹ E-mail: eddy.arteco@planet.nl.

s E-mail: j.h.willems@bio.uu.nl.
}

Am. Nat. 2006. Vol. 168, pp. 133-143. (c) 2006 by The University of Chicago. 0003-0147/2006/16802-41362\$15.00. All rights reserved.
All biological communities are spatially and temporally variable. Ecologists have long been fascinated with speciesarea curves and have documented how species richness accumulates with area, from the scale of individuals to that of the globe (Rosenzweig 1995; Hubbell 2001). Communities are also temporally dynamic in that they gain and lose species over time (MacArthur and Wilson 1967; van der Maarel and Sykes 1993). Although it is rarely recognized by ecologists, the spatial and temporal aspects of biodiversity are not independent (Preston 1960; van der Maarel 1993; Rosenzweig 1998; Adler and Lauenroth 2003; Adler 2004), in that the species composition of smaller areas must fluctuate more rapidly than that of larger contiguous areas. This interdependence of the spatial and temporal scaling of species richness has important implications for the investigation of the causes and consequences of biodiversity. The study of species-area curves is a case in point; much controversy has been associated with the spatial dependence of species richness at fine scales $(<10,000$ $\mathrm{m}^{2}$ ) versus larger, regional scales (Connor and McCoy 1979; Rosenzweig 1995). Fine-scale spatial patterns exhibit a faster rate of species accumulation in space than largerscale patterns (Williams 1964; Rosenzweig 1995) and are often described by different models (Arrhenius 1921; Gleason 1922; Kylin 1926; He and Legendre 1996; Fridley et al. 2005). Although these inconsistencies have been explained away on both biological and statistical grounds (Connor and McCoy 1979; Rosenzweig 1995; He and Legendre 1996; Hubbell 2001), few studies have explicitly recognized the greater temporal dependence of fine-scale data or considered whether species-area relationships should fundamentally depend on the temporal stability of populations at different spatial scales.

The species richness of small samples-those captured in small areas or short sampling durations-is constrained by the total number of individuals in a sample, regardless of the importance of ecological processes such as competition or local niche partitioning (Fisher et al. 1943; Gotelli and Colwell 2001; White 2004). Williams (1943) and Preston (1960) were among the first to recognize that both species-area and species-time curves should be dom- 
inated by such "sampling" processes at small areas or durations, and Preston (1960) explicitly addressed whether species accumulation in space and time are related-his "ergodic conjecture" (Rosenzweig 1998). Recent renewed interest in Preston's hypothesis (Rosenzweig 1998; Adler and Lauenroth 2003; Adler 2004; White 2004) has supported Preston's case that species-area and species-time curves are qualitatively similar and are underlain by the same processes. However, Preston's hypothesis also suggests that classic debates over the behavior of species-area curves, particularly those for plants (Arrhenius 1921; Gleason 1922; Williams 1964; Rosenzweig 1995; He and Legendre 1996; Hubbell 2001), may be resolved by incorporating the increasing dependence of smaller-area samples on the temporal duration of community surveys. Adler and Lauenroth (2003) and Adler et al. (2005) presented evidence that fine-scale accumulation rates of plant richness may decrease over time, although its significance to full-scale species-area curves was not addressed in their studies. Following Williams (1943) and Preston (1960), we further suggest that the accumulation of species over time in small-area samples can be used to estimate and subsequently correct for the influence of sampling processes in fine-scale species-area curves and thus could potentially reconcile the spatial scaling of species richness at local and regional scales (Smith et al. 2005).

In light of increasing interest in the relationship between accumulation patterns of species richness in space and time (Rosenzweig 1998; Adler and Lauenroth 2003; Adler 2004; White 2004), we ask whether "correcting" fine-scale spatial-richness data by accumulating richness over time in small spatial samples reconciles fine-scale species-area curves with those of the regions in which they are embedded. Addition of a temporal component to speciesarea curves should be especially important in communities that exhibit sufficient year-to-year fluctuation in species composition to allow temporal accumulations over the scale of a few years to generate a much larger sample size for small quadrats. We use plant community survey data from three floristically separate perennial grassland communities that, by means of regular disturbance from fire, grazing, or drought, display yearly turnover in fine-scale species composition. We hypothesize that fine-scale species-area curves are strongly constrained by the sampling of too few individuals and that such constraints can be alleviated through the analysis of temporal species accumulation for quadrats of different sizes.

\section{Removing Sampling Effects from Fine-Scale Richness Values}

As with species-area relationships, the rate at which species richness accumulates over time for a given area is a func- tion of both sampling and ecological processes (Rosenzweig 1998; Adler and Lauenroth 2003; White 2004; Adler et al. 2005). Although the accumulation of species over relatively short temporal durations is thought to be largely the result of sampling processes (Preston 1960; White 2004; Fridley et al. 2005; White et al. 2006), there remains the possibility that some ecological process, such as a shift in local environmental properties, contributes to the rate at which species accumulate from year to year. The problem becomes one of isolating the proportion of richness increase that comes only from obtaining a larger sample of individuals (sampling) from the proportion that would occur even if the number of individuals in one sample were very large (ecological). This can be done by holding the influence of one process constant and calculating the rate at which richness increases by systematically varying the other.

If a large proportion of the individuals in a sample turn over from year to year and the density of individuals $(N)$ in the sample is relatively constant over time, then the accumulated richness from adding one temporal survey of a fixed quadrat to that of another $(\Delta S)$ should bear a constant signature of sampling (i.e., $N$ to $2 N$ ), regardless of the temporal extent between surveys. However, the ecological influence on $\Delta S$ should be a function of temporal extent, assuming that environments on average become less similar with the passage of time (analogous to the spatial concept of distance decay of similarity; Nekola and White 1999). Thus, comparison of how richness accumulates for a variety of two-time surveys of a single quadrat (e.g., comparing the number of new species gained after 5 years with the number gained after 10 years) allows an estimate of the unique contribution of ecological processes to the increase in richness. Subsequent removal of this component from $\Delta S$ suggests the rate at which richness increases from one sample to two samples in the absence of ecological processes, and this rate can be used in a sampling-only model to estimate the richness of a sample, given infinite individuals (i.e., a samplingindependent estimate of richness for a given quadrat size).

The approach of partitioning sampling and ecological components is illustrated in figure 1 , where a single quadrat is surveyed three different times, $t_{1}, t_{2}$, and $t_{3}$. The increases in richness from $t_{1}$ to $t_{2}$ and from $t_{1}$ to $t_{3}$ are products of both a larger sample size of individuals and ecological processes operating over time. The sampling component is dependent only on the number of samples (here, surveys of a given quadrat) and can be described with the Monod (Michaelis-Menten) function $V N /(K+N)$, where richness approaches asymptote $V$ at rate $K$, given $N$ samples. Because the influence of sampling is the same for the richness of $t_{1}+t_{2}$ as for that of $t_{1}+t_{3}$, the difference in accumulated richness between these two-sample populations is a function 


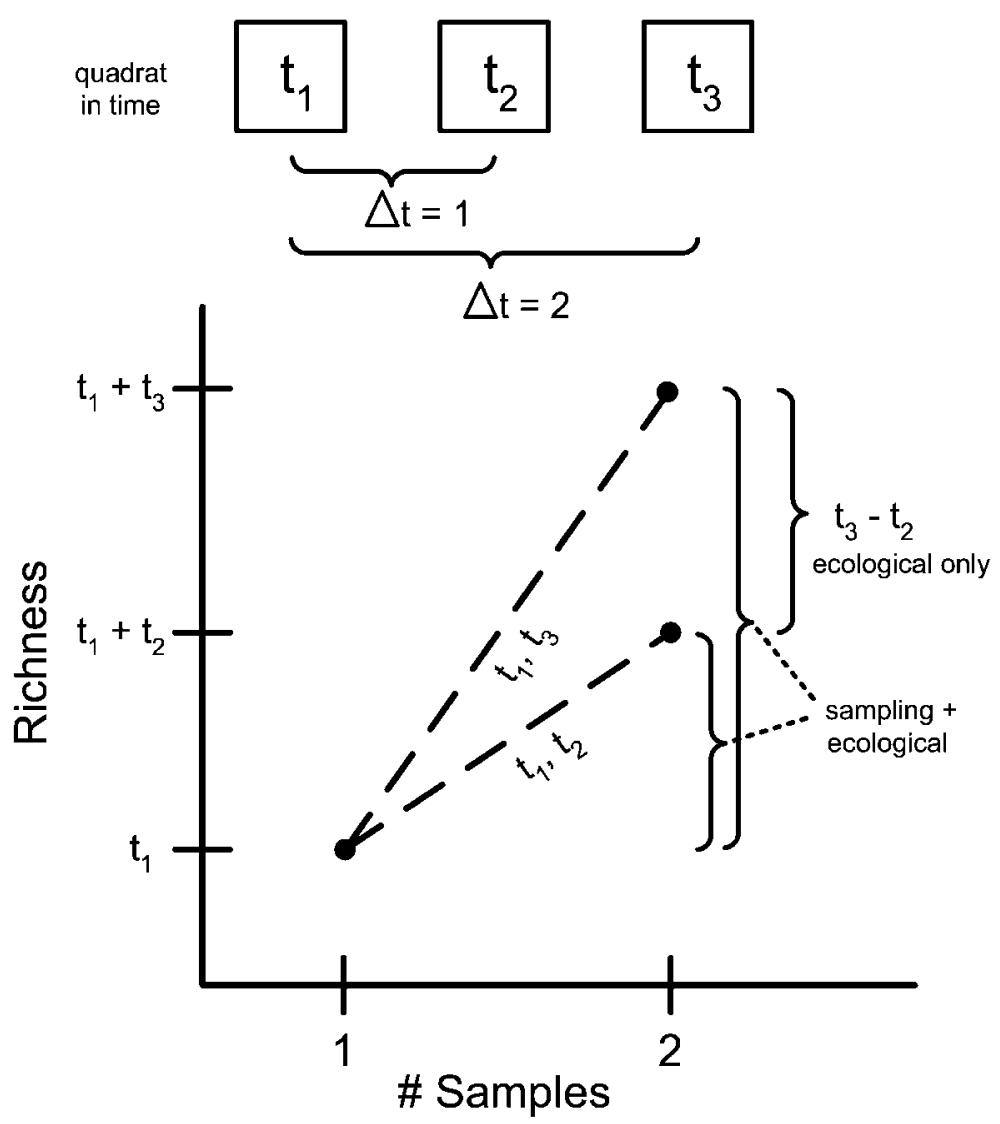

Figure 1: Separation of sampling and ecological influences on species richness by comparison of the increase of richness in two pairs of plots of different temporal extents. The figure illustrates the richness of one quadrat surveyed at three different times. The increase in richness from $t_{1}$ to $t_{2}$ is a product of both a larger sample size of individuals ("sampling") and ecological processes such as environmental heterogeneity ("ecological"). Because $t_{1}$ and $t_{3}$ differ more in temporal extent than $t_{1}$ and $t_{2}$, the increase in richness when adding $t_{3}$ to $t_{1}$ should be greater than that of adding $t_{1}$ and $t_{2}$, but the influence of sampling should be the same. Thus, the difference in accumulated richness between $t_{3}$ and $t_{2}$ should be a function of ecological processes only, and isolation of ecological processes allows the estimation of the degree to which sampling processes influence the richness of a particular quadrat size.

of only ecological processes. Ecological influences on species accumulation in relation to space or time are often modeled as power functions (Adler and Lauenroth 2003; Fridley et al. 2005), and here we are interested in how $\Delta S$ changes as a function of temporal extent: $\Delta S=c T^{Y}$, where $c$ and $Y$ are parameters describing the rate at which new species are added with time between surveys. Note that $Y$ is not strictly analogous to the $Z$ of species-area curves (or the $W$ of species-time curves; Adler and Lauenroth 2003) because $T$ in our formulation describes temporal extent between any two samples, rather than accumulation. If richness is an additive function of sampling and ecological components, the following set of equations describes how richness accumulates in the above example. The richness of the quadrat at time $1\left(S_{1}\right)$ involves only one sample at a single point in time and is described by

$$
S_{1}=\frac{V}{K+1}
$$

The accumulated richness from adding a second sample to that of time 1 depends on both the sample size and the temporal extent between surveys, so that

$$
\begin{aligned}
& S_{12}=\frac{2 V}{K+2}+c T_{12}^{Y}, \\
& S_{13}=\frac{2 V}{K+2}+c T_{13}^{Y},
\end{aligned}
$$

where $S_{12}$ is the total richness of surveys at times 1 and 2, $S_{13}$ is the total richness of surveys at times 1 and 3 (given $\left.\left[t_{3}-t_{1}\right]>\left[t_{2}-t_{1}\right]\right)$, and $T_{i j}$ is the temporal extent between 
surveys $i$ and $j$ of the same quadrat. Because all $S$ and $T$ are known, the last two equations can be combined to estimate $c$ and $Y$ :

$$
S_{13}-S_{12}=c T_{13}^{Y}-c T_{12}^{Y}
$$

With fitted estimates of $Y$ for each scale, $V$ and $K$ can be estimated via maximum likelihood using equations (1)(3). Parameter $V$ is of particular significance because it is the estimate of the richness of a particular quadrat size, given infinite samples (i.e., with the influence of sampling processes removed). Determination of $V$ for each scale thus allows examination of a sampling-independent finescale species-area curve.

Note that the choice of asymptotic and power functions for sampling and ecological species accumulation, respectively, reflects only the general way in which these effects have been modeled by past researchers (cf. Flather 1996; Gotelli and Colwell 2001; Tjørve 2003) and is not required for our general approach of separating these two processes with spatiotemporal composition data. For example, the ecological component could be modeled with linear or exponential functions (He and Legendre 1996) or a large variety of more complicated accumulation functions (Flather 1996; Tjørve 2003), depending on the nature of the data.

\section{Methods and Data}

For each of three temperate grasslands, by constructing multiple species-area curves using different survey durations of each quadrat size, we document that fine-scale species-area curves change as richness accumulates over time (fig. 2). We log transform fine-scale richness data for the purposes of integrating fine-scale patterns into full-scale ("global"), nested species-area curves originating from each site (Fridley et al. 2005). We then ask what proportion of the temporal accumulation in richness of each quadrat size is the result of sampling versus ecological processes by applying the method described above, which consists of first separating sampling and ecological components of richness estimates using time series data for each quadrat and then estimating the sampling-independent richness values for each quadrat size using the sampling component of richness only. With estimates of sampling-corrected species-area curves for each grassland (up to $2 \mathrm{~m}^{2}$ in area) in hand, we ask how these modified fine-scale curves fit within the context of a localto-global species-area curve starting within each grassland. We assume that species richness values of large areas (hundreds of $\mathrm{km}^{2}$ and above) are not significantly influenced by sampling processes and do not change significantly within the time span of this study.

We used vascular plant species richness data collected from three floristically separate grasslands that are among the most diverse communities at these scales in the world (>35 species $\mathrm{m}^{-2}$ ): moist longleaf pine (Pinus palustris) savanna from southeastern North Carolina $\left(34^{\circ} 5^{\prime} \mathrm{N}\right.$, $78^{\circ} 18^{\prime} \mathrm{W}$; hereafter NC), chalk grassland from South Limburg, The Netherlands $\left(50^{\circ} 52^{\prime} \mathrm{N}, 5^{\circ} 55^{\prime} \mathrm{E}\right.$; hereafter NL), and the seasonally dry Great Alvar (limestone) grassland from Gettlinge $\left(56^{\circ} 23^{\prime} \mathrm{N}, 16^{\circ} 27^{\prime} \mathrm{E}\right)$ on the Swedish island of Öland (hereafter SE). Sites are described in more detail by Sykes et al. (1994), Willems et al. (1993), and van der Maarel and Sykes (1993), respectively. Although the species composition of each site exhibits considerable year-to-year variation (van der Maarel and Sykes 1993), the vast majority of all species observed at each site are perennials characteristic of oligotrophic soils, including 106 out of 112 species in NC, 84 out of 94 species in NL, and 78 out of 92 species in SE. Most of the few annual species at each site cope with the low soil fertility by means of hemiparasitism. Species composition at all sites was surveyed in fully nested quadrats of $0.001,0.01,0.25,1.0$, and $2.0 \mathrm{~m}^{2}$ in area, laid out in replicate blocks of three in $\mathrm{NC}$ and $\mathrm{NL}$ and in one replicate in SE. Each $2-\mathrm{m}^{2}$ quadrat included two $1-\mathrm{m}^{2}$ quadrats, eight $0.25-\mathrm{m}^{2}$ quadrats, and 40 of each of the two smallest sizes of quadrat. Species composition was surveyed annually from 1985 to 1997 in SE and annually from 1985 to 1989 and again in 1994 in NC and NL. Because species were not recorded during 1990-1993 in NC and NL, we use only the 1994 survey to separate ecological and sampling processes with temporal extent (eq. [4]) and do not consider species-time curves after the 5 years of temporally contiguous data. Species were recorded with rooted presence in NC and NL and with shoot presence in SE (Sykes et al. 1994).

We calculated sampling-independent richness estimates for each quadrat size in each site separately. For a given quadrat size, we selected each unique quadrat in turn and for it determined every unique pairwise temporal comparison of surveys that share the first year. For NC and NL, 20 unique temporal comparisons were possible for each quadrat (e.g., 1985-1986 vs. 1985-1987, 1985-1987 vs. 1985-1988, and so on, to 1988-1989 vs. 1988-1994). For the more extensive 13-year annual survey of the SE site, 285 such contrasts were available for each quadrat. For each of these contrasts, we calculated the temporal extent of each pair $\left(T_{12}\right.$ and $\left.T_{13}\right)$, the richness of the quadrat in the first survey $\left(S_{1}\right)$, and its accumulated richness for each associated temporal extent $\left(S_{12}\right.$ and $\left.S_{13}\right)$. For each quadrat size and site, we estimated $Y$ in equation (4) with simple linear regression after taking the logarithm of both sides of equations (2) and (3), and we then used these parameter estimates in equations (1)-(3) to calculate maximum likelihood estimates of $V$ and $K$. Note that parameter $c$ does not have to be estimated with $\log$ transfor- 

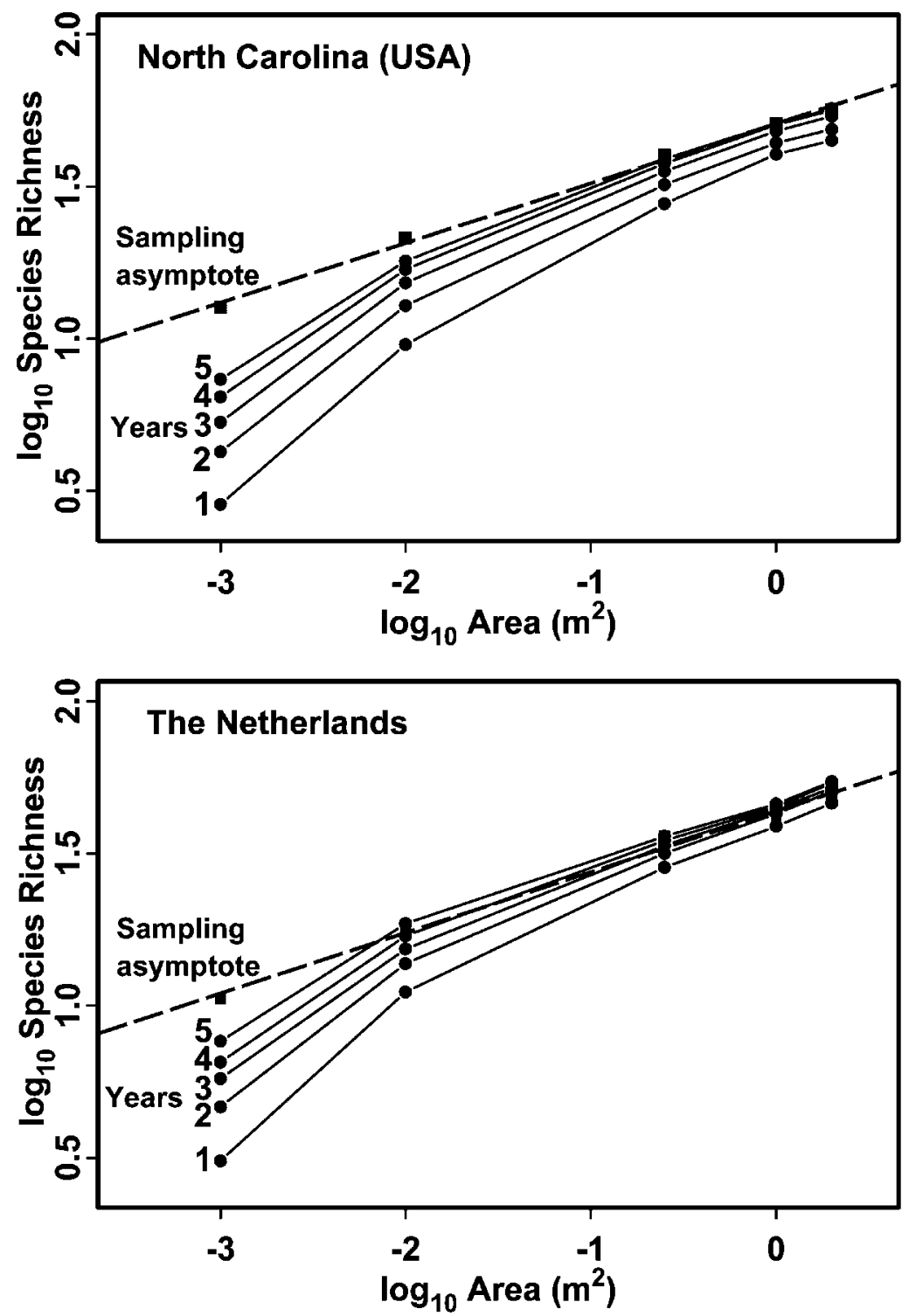

Figure 2: Variation in the shape of the fine-scale species-area curve over different intervals of time, for grasslands in North Carolina and the Netherlands. Solid lines and circles indicate mean species-area values (mean of three blocks) accumulated over 1-5 years. Squares indicate estimates of single-time richness after correction for sampling processes, with dashed line indicating linear least squares regression.

mation because $\log (c)$ drops out when taking the difference of equations (2) and (3). We implemented linear least squares and maximum likelihood fitting in $\mathrm{R}$ 2.2.0 (R Development Core Team 2005). We also note that nested species richness values are not independent either in space or in time; while this does not bias mean fitted parameter estimates, it precludes unbiased estimation of their confidence intervals (see Adler and Lauenroth 2003; Colwell et al. 2004), so we report mean estimates only. With such fine-scale surveys of sessile organisms, we do not consider errors in species detection (Cam et al. 2002) to significantly influence our estimates of species richness. We explored other functions for modeling both the ecological and sampling components of accumulated richness in time (asymptotic, exponential, and linear for ecological functions; negative exponential for the asymptotic sampling function), but the Monod and power functions performed as well as or better than the competing models (as assessed with the Akaike Information Criterion) in most instances; for simplicity, we used them in all cases. 
Although yearly species turnover has been shown to be considerable in these communities, we were concerned that our calculation of the sampling component of species accumulation could be underestimated if annual turnover was at times insufficient to effectively generate new samples from one year to the next, thus spuriously inflating our estimation of ecologically driven temporal change. To independently assess whether our method of separating ecological and sampling components of richness does in fact separate change due to sampling effects from temporal trends in species composition, we subjected species composition data for each site to canonical correspondence analysis (CCA; Ter Braak 1986). As a constrained (direct) ordination technique, CCA maximizes the correlation between a chosen "environmental" gradient-in our case, time-and variation in species composition (Palmer 1993). Our use of CCA thus reflects our desire to quantify the extent to which species composition exhibits directional change over time at different scales, indicating the strength of the ecological component in temporal species accumulation. For each site and scale, we created a species presence-absence matrix composed of all unique quadrats at each available time period. These matrices were subjected to CCA with survey year as the constraining axis, using the VEGAN 1.6-10 statistical package for R 2.2.0 (Oksanen et al. 2005). Results of CCA include a statistical measure of how well species composition is explained by the constrained axis of time ("constrained inertia"), which we report for each spatial scale at each site.

\section{Fine-Scale Species-Area Curves over Time}

For each site, species-area curves measured at a single time are consistent with those of fine-scale plant communities from a variety of other habitats in that they exhibit relatively high accumulation rates (measured as the $Z$ value, or log-log slope of the species-area relation) compared to the species-area relations of landscapes and regions (Preston 1960; Rosenzweig 1995; Hubbell 2001; Fridley et al. 2005). Values of $Z$ for 1 -year species-area curves were 0.36 , 0.34 , and 0.24 for the NC, NL, and SE sites, respectively (figs. 2, 3A). The low $Z$ value for SE is partly the result of slightly higher estimated richness values for the smallest scales caused by a different survey method (measuring shoot presences in addition to rooted presences) and has negligible influence on richness estimates for quadrats larger than $0.01 \mathrm{~m}^{2}$ or subsequent time periods (Sykes et al. 1994).

Over time, smaller quadrats accumulate species more quickly, thus causing a steady decrease in the rate of species accumulation in space for each site (figs. 2, 3). After 13 years, the accumulated species-area curve for alvar grassland in SE remains well described by a straight line in log- log space ( $R^{2}>0.99$ for all time periods), and the $Z$ value is roughly halved, from 0.24 to 0.13 (fig. $3 B$ ). Similarly, after 5 years, species-area curve $Z$ values for NC pine savanna and NL chalk grassland decrease from 0.36 to 0.28 and from 0.34 to 0.25 , respectively (fig. 2).

When species-time curves are used to estimate the ecological and sampling components of species accumulation for each quadrat size, the sampling-independent estimates of richness also exhibit a significantly reduced fine-scale $Z$ value, as compared to those measured at a single point in time (figs. 2, 3A). Parameter estimates for ecological and sampling components of the accumulation of richness in time for each site are presented in table 1 . As expected, smaller quadrat sizes are substantially more sensitive to sampling constraints. On average, single surveys of our smallest quadrat size $\left(0.001 \mathrm{~m}^{2}\right)$ consist of only $22 \%-37 \%$ of the estimated richness after we correct for sampling constraints. Even at a size of $2 \mathrm{~m}^{2}$, which may contain thousands of individuals, single surveys account for only about $80 \%$ of the expected richness after sampling correction (table 1). For all three grasslands, the linear log$\log$ fit of species-area relationships is slightly improved with sampling correction $\left(R^{2}\right.$ improves to 0.99 from 0.97 for NC and NL and to 0.99 from 0.98 for SE), with $Z$ values of $0.19,0.18$, and 0.13 for $\mathrm{NC}, \mathrm{NL}$, and $\mathrm{SE}$, respectively.

Ecological processes, as represented by temporal extent, had a minor influence on species-time curves for all sites, as suggested by $Y$ values near 0 and a consistently small proportion of variance explained by time axes in CCA (table 1). For NC pine savanna, sampling constraints are such that sampling-corrected richness values for 1- and 2$\mathrm{m}^{2}$ quadrats are approached only after $4-5$ years; richness of the smallest quadrat sizes is still significantly underestimated after 5 years (fig. 2). Species accumulate faster over time for NL chalk grassland, so that richness values match those of sampling-independent estimates after only 2-3 years for all quadrat sizes except the smallest (fig. 2). The faster rate of turnover for NL is verified by CCA results documenting a larger proportion of variance in species composition accounted for by time than that of $\mathrm{NC}$ or $\mathrm{SE}$ and by consistently higher estimates of the ecological component $Y$ in temporal species accumulations (table 1). Greater directional change in species composition over time at the NL site is likely due to substantial eutrophication through atmospheric nitrogen deposition (Bobbink 1991; Willems et al. 1993; Bobbink et al. 1998). Richness of SE alvar grassland after 6 years begins to approach sampling-corrected values for all quadrat sizes (fig. 3 ), and the temporal accumulation of species bears almost no signature of ecological processes ( $Y$ in table 1), even considering its longer 13-year time series. This is consistent with the current model of diversity dynamics in this system as 

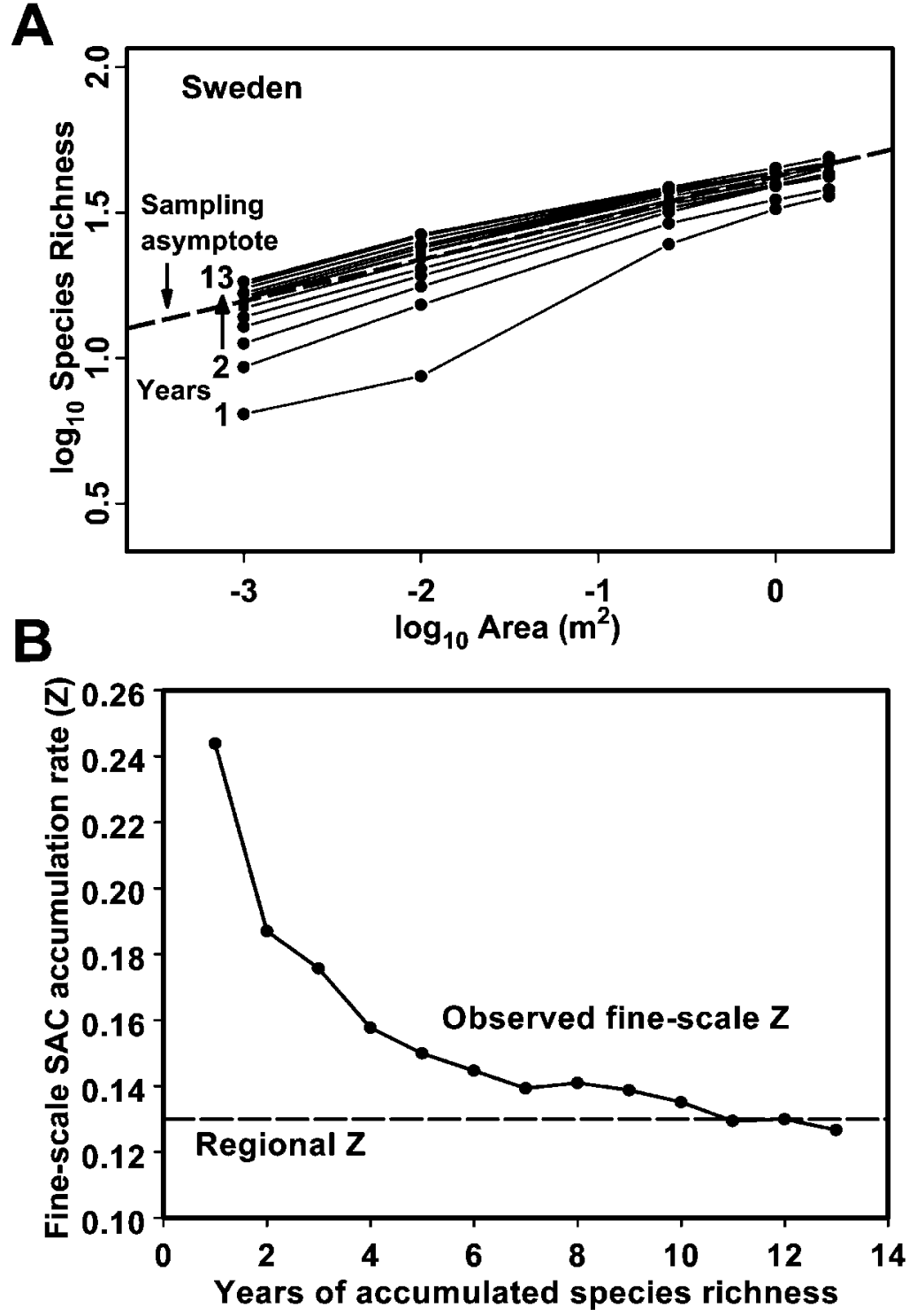

Figure 3: A, Variation in the shape of the fine-scale species-area curve over different integrals through time, for Swedish alvar grassland over 13 years. Dashed line indicates the least squares regression line for single-time estimates of richness that are not influenced by sampling processes. $B$, Change in the slope $\left(Z\right.$ value) of the fine-scale $\left(0.001-2 \mathrm{~m}^{2}\right)$ species-area curve as species richness is accumulated over a 13-year period in Sweden. Over time, the fine-scale $Z$ value decreases toward the regional species-area curve's $Z$ value (dashed line), estimated as the log-log slope of the mean richness of the $2-\mathrm{m}^{2}$ alvar quadrat (36 species) and the floristic richness of the Great Alvar region (388 species in ca. $\left.250 \mathrm{~km}^{2}\right)$. This is the same value $(0.13)$ as the sampling-independent fine-scale $Z$ estimate shown in $A$.

being largely the product of stochastic mortality and recruitment but driven in part by frequent droughts (van der Maarel and Sykes 1993).

Reconciling Fine- and Broad-Scale Species-Area Curves

When put within the context of global nested species-area curves originating within each grassland, our estimated sampling-corrected rates of species accumulation help reconcile the species-area relationships of fine scales and those of whole landscapes and regions (fig. 4). For NC pine savanna, sampling-corrected species-area curves exhibit a rate of species accumulation (0.19) similar to the value of 0.16 for areas ranging from $2-\mathrm{m}^{2}$ quadrats to all of Brunswick County, North Carolina (1,300 species, 2,165 km² U.S. Department of Agriculture 2004), after which the 
Table 1: Results of canonical correspondence analysis (CCA) and fitted parameters of ecological and sampling functions of the accumulation of species richness for five nested quadrat sizes in three grasslands

\begin{tabular}{lcccccc}
\hline $\begin{array}{l}\text { Location and } \\
\text { area }\left(\mathrm{m}^{2}\right)\end{array}$ & $\begin{array}{c}\text { CCA variance } \\
\text { explained by } \\
\text { time }(\%)\end{array}$ & $\begin{array}{c}\text { Temporal } \\
\text { extent rate } \\
(Y)\end{array}$ & $\begin{array}{c}\text { Sampling } \\
\text { asymptote }(V)\end{array}$ & $\begin{array}{c}\text { Sampling } \\
\text { rate }(K)\end{array}$ & $\begin{array}{c}\text { One-survey } \\
\text { richness }\end{array}$ & $\begin{array}{c}\text { Richness as } \\
\text { proportion } \\
\text { of } V(\%)\end{array}$ \\
\hline $\begin{array}{l}\text { North Carolina: } \\
2\end{array}$ & 4.2 & .033 & 56.37 & .23 & 44.8 & 79 \\
1 & 3.6 & .030 & 50.78 & .23 & 40.4 & 79 \\
.25 & 3.1 & .037 & 39.80 & .39 & 27.8 & 70 \\
.01 & 2.1 & .026 & 21.02 & .99 & 9.6 & 46 \\
.001 & 5.0 & .031 & 13.22 & 3.46 & 2.9 & 22 \\
The Netherlands: & & & & & & \\
2 & 9.8 & .054 & 48.19 & .11 & 40.7 & 85 \\
1 & 7.2 & .056 & 42.05 & .12 & 38.8 & 92 \\
.25 & 5.7 & .066 & 35.96 & .38 & 28.4 & 79 \\
.01 & 7.7 & .111 & 17.28 & .78 & 11.1 & 64 \\
.001 & 12.0 & -.013 & 12.35 & 3.31 & 3.1 & 25 \\
Sweden: & & & & & & \\
2 & 5.5 & -.009 & 45.59 & .22 & 36.3 & 80 \\
1 & 4.9 & -.001 & 41.31 & .22 & 33.2 & 80 \\
.25 & 4.2 & .004 & 34.71 & .30 & 24.6 & 71 \\
.01 & 5.2 & -.009 & 24.73 & .98 & 12.6 & 51 \\
.001 & 6.3 & -.018 & 15.69 & 1.24 & 5.7 & 37 \\
\hline
\end{tabular}

Note: CCA variance explained by time is the CCA constrained inertia of the time axis (axis 1) and reflects the directional change in species composition over time. Power model rate parameter $Y$ was obtained from a log-transformed linear model of equation (4) of the sampling-independent increase in richness as temporal extent increases in a contrast of a single quadrat surveyed at two time periods. Sampling parameters $V$ and $K$ were obtained from the Monod function fitted via maximum likelihood using equations (1)-(3). One-survey richness is the average single-time richness value of each quadrat size and is followed by the proportion of the estimated sampling-independent richness value $(V)$ that the one-survey value represents.

accumulation rate increases to reach the global richness value of ca. 250,000 species (Govaerts 2001; Thorne 2002; U.S. data from Kartesz 1999). Similarly, a samplingcorrected richness accumulation rate of 0.18 approximates the rate of 0.16 measured in the southern part of the province of Limburg (1,005 species, $723 \mathrm{~km}^{2}$; Blink 1997) and over all of the Netherlands (1,357 species, $33,900 \mathrm{~km}^{2}$; van der Maarel 1971).

The global nested species-area curve from within the Great Alvar region of Öland, Sweden, is punctuated between this region $\left(388\right.$ species, $250 \mathrm{~km}^{2}$; van der Maarel $1988)$ and the entire island (1,050 species, $1,350 \mathrm{~km}^{2}$; Lundqvist 1986). The alvar is unusual in that a large part of its area is species-poor limestone pavement that constitutes an extreme habitat for plants, while potentially rich habitats such as fertile forest and limestone marsh occupy only small areas (van der Maarel 1988). On the other hand, the island of Öland as a whole is unusually diversified and contains far more species than an average Swedish area of this size (Lundqvist 1986). Consequently, the samplingcorrected fine-scale species accumulation rate of the alvar plant community is equal to that of larger areas within the alvar (0.13), rather than that of the entirety of Öland or larger areas in Sweden.

\section{Discussion}

For all three grasslands, our analysis demonstrates that fine-scale, single-survey richness estimates are significantly constrained by sampling processes and that correction for such processes may help reconcile the lower and middle portions of the global species-area curve. The similarity between sampling-corrected, fine-scale $Z$ values and $Z$ values of broader scales renews the suggestion that species richness observes the same scaling relation as within a biotic province (Rosenzweig 1995; Rosenzweig and Ziv 1999; cf. Smith et al. 2005), revealing the signature of ecological processes that may obey the same spatial scaling laws at fine scales that occur at much larger scales (Smith et al. 2005; cf. Crawley and Harral 2001). However, our global species-area curves also suggest that species accumulation rates begin to accelerate at areas of ca. $10^{4}-10^{5}$ $\mathrm{km}^{2}$, which are smaller than areas typically considered to be separate biotic provinces (Good 1974; Rosenzweig 1995). The cause of this point of acceleration in the rate of species accumulation remains a compelling and unresolved issue in biogeography (Preston 1960; Rosenzweig 1995; Crawley and Harral 2001; Hubbell 2001; Allen and White 2003). 

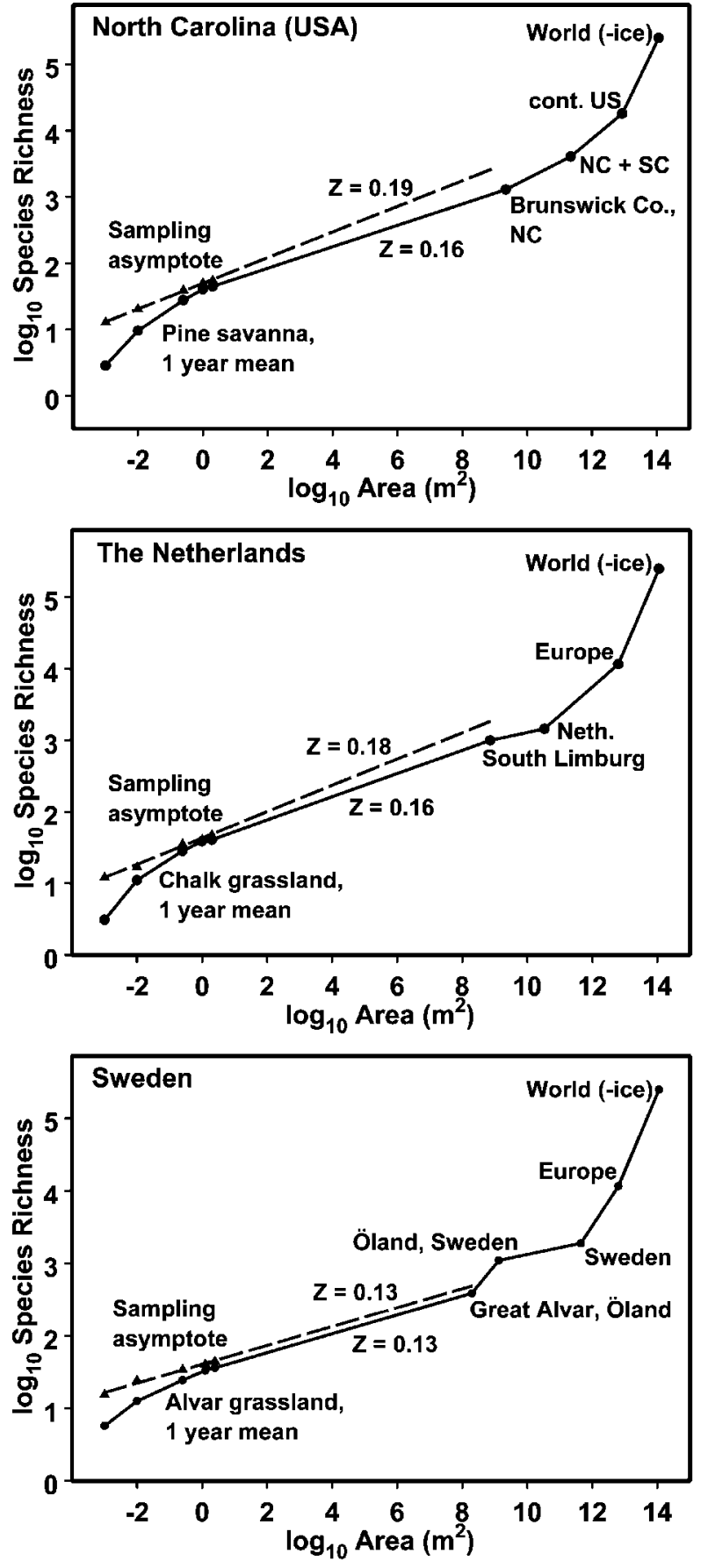

Figure 4: Fine-scale, sampling-independent species-area curves (triangles, with dashed least squares regression lines) superposed on species-area "snapshots" (circles) for the same communities, extended to regional, national, and global values of vascular plant richness. Lowest five values for each static curve are 1-year mean richness values for each quadrat size at each site. Sources for regional and national richness values are listed in the text.
In our analysis, we assume that larger-scale estimates are not significantly influenced by sampling processes, consistent with prevailing conceptual models of full-scale species-area curves (Preston 1960; Rosenzweig 1995). Large-area estimates of species richness are by necessity derived from long-term study and specimen collections, and thus they cannot be decomposed into yearly estimates. Moreover, temporal fluctuation in nested species-area values must necessarily decrease for larger areas, and there is no basis to conclude that the diversity values of very large areas change significantly from year to year. With log transformation, the change in richness over a 5- or 13year period would have to be in the hundreds or thousands of species to influence the species-area relations of large areas. We thus conclude that the species-area curves of broader scales do not significantly change over a period of several years.

Our analysis also includes the assumption that the turnover in individuals from year to year effectively generates new samples of individuals between survey years. In reality, because most of the species at each site are potentially perennial, only some fraction of the individuals in a quadrat turns over from year to year, a fraction that we assume to be roughly consistent between years. That only some fraction turns over each year does not invalidate our calculation of the sampling asymptote, however, because the estimate of the asymptote $V$ is insensitive to how samples are scaled (i.e., $N$ to $2 N$ vs. $N / 2$ to $N$ ). Although we do not have data on temporal turnover at the level of individuals, past analyses of temporal dynamics at these sites have suggested substantial rates of yearly individual turnover, as indicated by annual changes in species composition at small scales in the absence of changes in yearly species richness. These dynamics stem largely from frequent disturbances of annual fire, grazing, mowing, and drought (van der Maarel and Sykes 1993; Sykes et al. 1994). Users of our approach should be aware, however, that application of our method to communities of slow annual turnover could lead to overestimation of the ecological component in equation (4) because the greater species accumulation from adding quadrats of greater temporal extent could be driven in part by the larger number of new individuals obtained over time as individuals slowly die and are replaced. We recommend independent verification (such as with the CCA analysis used here) that $Y$ estimates make sense in the context of directional compositional change over time. Our CCA results suggest there is not a significant ecological component to temporal accumulation at any of our sites, a result that was mirrored by $Y$ estimates near (or even below) 0 . Indeed, we initially estimated the sampling-independent richness values using time series data where we ignored the ecological component entirely (modeling temporal accumulation only as 
a sampling [Monod] function) and obtained nearly identical sampling-independent $Z$ values for each site $(0.18$, 0.17 , and 0.13 , for NE, NL, and SE, respectively). Thus, although our analysis is appropriate for our sites and others where annual turnover is sufficiently high to generate new samples for the same quadrat over relatively short durations, it will be more difficult to apply to communities of mostly long-lived individuals.

That the species richness of small quadrats is significantly constrained by a lack of individuals, even in quadrats that contain hundreds of individuals, has important ramifications for studies of species diversity in plant communities outside the context of species-area curves. The study of diversity in grasslands has a long tradition of using relatively small (typically $1 \mathrm{~m}^{2}$ ) experimental units. If, as this study suggests, such quadrats are incomplete samples of the total number of species that could inhabit the area at a given time, then there may be a substantial noise component to diversity analyses that can be rectified only by taking a larger sample or by estimating samplingindependent richness values as we describe. For our three temperate grasslands, single-time richness estimates were as much as $20 \%$ below sampling-independent richness estimates even in quadrats of $2 \mathrm{~m}^{2}$, suggesting that sampling processes can be ignored only for much larger quadrats. Although from our data it is difficult to estimate the specific area at which sampling processes become negligible because our largest resurveyed area $\left(2 \mathrm{~m}^{2}\right)$ is fairly small, it should nonetheless be possible if time series data exist for a larger range of scales for a given habitat.

Although there is growing recognition that patterns of biodiversity must be addressed at multiple spatial scales (Palmer and White 1994; Crawley and Harral 2001), the addition of a temporal dimension to studies of scale dependency is a critical and heretofore missing step toward detecting the underlying causes of biodiversity patterns. Our results should be a strong mandate for local studies of communities to include estimates of compositional fluctuation, particularly at the smallest scales, where constraints on richness imposed by sampling are most significant. Coupling observations of spatial scale dependence to time series data will have major ramifications for the understanding of species richness in communities that exhibit large short-term compositional fluctuations (e.g., desert annuals, temporary wetlands, Mediterranean grasslands) because such fluctuations can provide critical information on the degree to which richness is controlled by sampling or ecological processes at multiple spatial scales. Our study thus renews Preston's (1960) suggestion that there are emergent organizing principles of biodiversity that may be uncovered by explicitly considering the interdependence of spatial and temporal species richness patterns across a wide spectrum of communities.

\section{Acknowledgments}

We gratefully acknowledge the collaboration of L. Bik, C. Norquist, E. Rosén, and J. Walker in establishment, maintenance, and monitoring of field plots. This work was supported by the National Science Foundation, the Swedish Natural Science Research Council, and Utrecht University. Öland data were collected when E.M. was at the Department of Plant Ecology, Uppsala University. J.D.F. was supported by the National Parks Ecological Research Fellowship program, a partnership between the National Park Service, the Ecological Society of America, and the National Park Foundation and funded through a generous grant from the Andrew W. Mellon Foundation. W. Ozinga assisted with richness data for the Netherlands, J. Weiss provided statistical help, and P. Adler provided valuable analytical insights.

\section{Literature Cited}

Adler, P. B. 2004. Neutral models fail to reproduce observed speciesarea and species-time relationships in Kansas grasslands. Ecology 85:1265-1272.

Adler, P. B., and W. K. Lauenroth. 2003. The power of time: spatiotemporal scaling of species diversity. Ecology Letters 6:749-756.

Adler, P. B., E. P. White, W. K. Lauenroth, D. M. Kaufman, A. Rassweiler, and J. A. Rusak. 2005. Evidence for a general species-timearea relationship. Ecology 86:2032-2039.

Allen, A. P., and E. P. White. 2003. Effects of range size on speciesarea relationships. Evolutionary Ecology Research 5:493-499.

Arrhenius, O. 1921. Species and area. Journal of Ecology 9:95-99.

Blink, E. N. 1997. Atlas van de Zuid-Limburgse flora 1980-1996. Stichting Natuurpublicaties Limburg, Maastricht.

Bobbink, R. 1991. Effects of nutrient enrichment in Dutch chalk grassland. Journal of Applied Ecology 28:28-41.

Bobbink, R., M. Hornung, and J. G. M. Roelofs. 1998. The effects of air-borne nitrogen pollutants on species diversity in natural and semi-natural European vegetation. Journal of Ecology 86:717-738.

Cam, E., J. D. Nichols, J. E. Hines, J. R. Sauer, R. Alipzar-Jara, and C. H. Flather. 2002. Disentangling sampling and ecological explanations underlying species-area relationships. Ecology 83:11181130.

Colwell, R. K., C. X. Mao, and J. Chang. 2004. Interpolating, extrapolating, and comparing incidence-based species accumulation curves. Ecology 85:2717-2727.

Connor, E. F., and E. D. McCoy. 1979. The statistics and biology of the species-area relationship. American Naturalist 113:791-833.

Crawley, M. J., and J. E. Harral. 2001. Scale dependence in plant biodiversity. Science 291:864-868.

Fisher, R. A., A. S. Corbet, and C. B. Williams. 1943. The relation between the number of species and the number of individuals in a random sample of an animal population. Journal of Animal Ecology 12:42-58.

Flather, C. H. 1996. Fitting species-accumulation functions and assessing regional land use impacts on avian diversity. Journal of Biogeography 23:155-168.

Fridley, J. D., R. K. Peet, P. S. White, and T. R. Wentworth. 2005. Connecting fine- and broad-scale patterns of species diversity: 
species-area relationships of southeastern U.S. flora. Ecology 86: $1172-1177$

Gleason, H. A. 1922. On the relation between species and area. Ecology 3:158-162.

Good, R. 1974. The geography of flowering plants. Longman, White Plains, NY.

Gotelli, N. J., and R. K. Colwell. 2001. Quantifying biodiversity: procedures and pitfalls in the measurement and comparison of species richness. Ecology Letters 4:379-391.

Govaerts, R. 2001. How many species of seed plants are there? Taxon 50:1085-1090.

He, F., and P. Legendre. 1996. On species-area relations. American Naturalist 148:719-737.

Hubbell, S. P. 2001. The unified neutral theory of biodiversity and biogeography. Princeton University Press, Princeton, NJ.

Kartesz, J. T. 1999. A synonymized checklist and atlas with biological attributes for the vascular flora of the United States, Canada, and Greenland. In J. T. Kartesz and C. A. Meacham, eds. Synthesis of the North American flora. Version 1.0. North Carolina Botanical Garden, Chapel Hill.

Kylin, H. 1926. Über Begriffsbildung und Statistik in der Pflanzensoziologie. Botaniska Notiser 1923:81-180.

Lundqvist, A., ed. 1986. Ölands kärlväxtflora av Rikard Sterner (Acta Phytogeographica Suecica 9, 1938). Förlagstjänsten, Stockholm.

MacArthur, R. H., and E. O. Wilson. 1967. The theory of island biogeography. Princeton University Press, Princeton, NJ.

Nekola, J. C., and P. S. White. 1999. The distance decay of similarity in biogeography and ecology. Journal of Biogeography 26:867878.

Oksanen, J., R. Kindt, and B. O'Hara. 2005. Vegan: R functions for vegetation ecologists. http://cc.oulu.fi/ jarioksa/softhelp/vegan.html.

Palmer, M. W. 1993. Putting things in even better order: the advantages of canonical correspondence analysis. Ecology 74:2215-2230.

Palmer, M. W., and P. S. White. 1994. Scale dependence and the species-area relationship. American Naturalist 144:717-740.

Preston, F. W. 1960. Time and space and the variation of species. Ecology 41:611-627.

Rosenzweig, M. L. 1995. Species diversity in space and time. Cambridge University Press, Cambridge.

- 1998. Preston's ergodic conjecture: the accumulation of species in space and time. Pages 311-348 in M. L. McKinney and J. A. Drake, eds. Biodiversity dynamics. Columbia University Press, New York.

R Development Core Team. 2005. R: a language and environment for statistical computing. Version 2.2.0. R Foundation for Statistical Computing, Vienna. http://www.r-project.org.

Rosenzweig, M. L., and Y. Ziv. 1999. The echo pattern of species diversity: pattern and process. Ecography 22:614-628.
Smith, V. H., B. L. Foster, J. P. Grover, R. D. Holt, M. A. Leibold, and F. deNoyelles Jr. 2005. Phytoplankton species richness scales consistently from laboratory microcosms to the world's oceans. Proceedings of the National Academy of Sciences of the USA 102: 4393-4396.

Sykes, M. T., E. van der Maarel, R. K. Peet, and J. H. Willems. 1994. High species mobility in species-rich plant communities: an intercontinental comparison. Folia Geobotanica et Phytotaxonomica 29:439-448.

Ter Braak, C. J. F. 1986. Canonical correspondence analysis: a new eigenvector technique for multivariate direct gradient analysis. Ecology 67:1167-1179.

Thorne, R. F. 2002. How many species of seed plants are there? Taxon 51:511-512.

Tjørve, E. 2003. Shapes and functions of species-area curves: a review of possible models. Journal of Biogeography 30:827-835.

U.S. Department of Agriculture. 2004. The PLANTS database. Version 3.5. National Plant Data Center, Baton Rouge, LA. http:// plants.usda.gov.

van der Maarel, E. 1971. Plant species diversity in relation to management. Pages 45-63 in E. Duffey and A. S. Watt, eds. The scientific management of animal and plant communities. Blackwell, Oxford.

- 1988. Floristic diversity and guild structure in the grasslands of Öland's Stora Alvar. Acta Phytogeographica Suecica 76:53-65.

. 1993. Plant species turnover and minimum area in a limestone grassland. Abstracta Botanica 17:173-178.

van der Maarel, E., and M. T. Sykes. 1993. Small-scale plant species turnover in a limestone grassland: the carousel model and some comments on the niche concept. Journal of Vegetation Science 4: $179-188$.

White, E. P. 2004. Two-phase species-time relationships in North American land birds. Ecology Letters 7:329-336.

White, E. P., P. B. Adler, W. K. Lauenroth, R. A. Gill, D. Greenberg, D. M. Kaufman, A. Rassweiler, et al. 2006. A comparison of the species-time relationship across ecosystems and taxonomic groups. Oikos 112:185-195.

Willems, J. H., R. K. Peet, and L. Bik. 1993. Changes in chalk grassland structure and species richness resulting from selective nutrient additions. Journal of Vegetation Science 4:203-212.

Williams, C. B. 1943. Area and number of species. Nature 152:264267.

1964. Patterns in the balance of nature. Academic Press, London.
Associate Editor: Curtis H. Flather Editor: Jonathan B. Losos 